http://doi.org/10.35784/iapgos.2583

\title{
MAGNETOELECTRIC COUPLING MEASUREMENT TECHNIQUES IN MULTIFERROIC MATERIALS
}

\author{
Jakub Grotel \\ Lublin University of Technology, Faculty of Electrical Engineering and Computer Science, Lublin, Poland
}

Abstract. Magnetoelectric multiferroics are solid-state materials which exhibit a coupling between ferroelectric and magnetic orders. This phenomenon is known as the magnetoelectric (ME) effect. Multiferroic materials possess a wide range of potential applications in such fields as metrology, electronics, energy harvesting \& conversion, and medicine. Multiferroic research is facing two main challenges. Firstly, scientists are continuously trying to obtain a material with sufficiently strong, room-temperature ME coupling that would enable its commercial application. Secondly, the measurement techniques used in multiferroic research are often problematic to implement in a laboratory setting and fail to yield reproducible results. The aim of the present work is to discuss three most commonly used methods in multiferroic studies; the lock-in technique, the Sawyer-Tower (S-T) circuit and dielectric constant measurements. The paper opens with a general description of multiferroics which is followed by mathematical representation of the ME effect. The main body deals with the description of the aforementioned measurement techniques. The article closes with a conclusion and outlook for future research.

Keywords: multiferroics, magnetoelectric effect, Sawyer-Tower circuit, magnetocapacitance

\section{METODY POMIARU SPRZĘ̇̇ENIA MAGNETOELEKTRYCZNEGO W MATERIALACH MULTIFERROICZNYCH}

\begin{abstract}
Streszczenie. Magnetoelektryczne multiferroiki należa do grupy materiałów, które wykazuja sprzężenie pomiędzy uprządkowaniem ferroelektrycznym a magnetycznym. Zjawisko to nosi nazwę sprzężenia magnetoelektrycznego (ME). Multiferroiki posiadaja szereg potencjalnych zastosowań w takich dziedzinach jak metrologia, elektronika, pozyskiwanie $i$ konwersja energii czy medycyna. Badania nad multiferroikami stoja przed dwoma głównymi wyzwaniami. Po pierwsze, naukowcy nieustannie próbuja uzyskać materiat o wystarczajaco silnym sprzężeniu ME $w$ temperaturze pokojowej, który umożliwitby jego komercyjne zastosowanie. Po drugie, techniki pomiarowe stosowane w badaniach multiferroików sa często problematyczne we wdrażaniu ich $w$ warunkach laboratoryjnych i nie umożliwiaja otrzymania powtarzalnych wyników. Celem niniejszej pracy jest omówienie trzech najczęściej stosowanych metod w badaniach nad multiferroikami; techniki lock-in, mostka Sawyera-Towera (S-T) i pomiarów stałej dielektrycznej. Artykut rozpoczyna się od ogólnego opisu multiferroików, po którym następuje matematyczne przedstawienie efektu ME. W głównej części omówiono wyżej wymienione techniki pomiarowe. Artykut zamyka podsumowanie i perspektywy przyszlych badań.
\end{abstract}

Słowa kluczowe: multiferroiki, efekt magnetoelektryczny, mostek Sawyera-Towera, magnetopojemność

\section{Introduction}

Multiferroics are a class of solid-state materials which combine two or more primary ferroic orders simultaneously in the same phase. The primary ferroic orders include ferromagnetism, ferroelectricity and ferroelasticity. Possible interactions between these orders are indicated in Fig. $1[9,25]$.

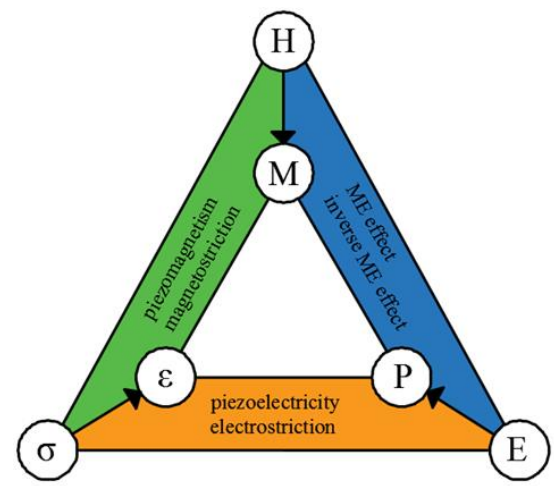

Fig. 1. Interactions between ferroic orders: $E$ - electric field, $P$ - polarization, $H$ - magnetic field, $M$ - magnetization, $\sigma-$ stress, $\varepsilon-$ strain

Magnetoelectric (ME) effect is a coupling between magnetic and ferroelectric orders in a material. It can be expected that exposure of such a multiferroic compound to a magnetic field $H$ will induce an electric polarization $P$. Conversely, placing the material in an electric field $E$ should result in changes to its magnetization $M[9,14,25]$. If the changes are linear in nature, the strength of this coupling is characterized by the magnetoelectric coupling coefficient $\alpha$ [28].

According to the formal nomenclature, a material that exhibits the ME coupling is called a magnetoelectric multiferroic. Due to immense interest in this form of coupling, the scientific community has reverted to the general name 'multiferroic' and nowadays the terms are used interchangeably unless explicitly stated otherwise [9].
The history of multiferroics can be traced back to the late 19th century and the research of Wilhelm Röntgen and Pierre Curie $[14,25]$. Further experiments were conducted in the former Soviet Union on boracites in the late 1950s and 1960s by G. Smolenskii, A. Ioffe and Y. Venevtsev. By the 1990s, numerous theories and models had been put forward along with novel experimental techniques which resulted in the revival of this field of study $[9,14,25]$. The term "multiferroic" itself originates from the MEIPIC-2 conference held in 1993 [9]. The next turning point came with the arrival of the 21 st century. In 2001, N. Spaldin held the first meeting of the American Physical Society solely dedicated to multiferroic materials. With the discovery of new compounds and mechanisms behind the ME coupling, the number of publications increased exponentially $[14,25]$. Nowadays, the field of study is continuing to develop at a dynamic rate with thousands of papers being published every year [29].

For many years, scientists had been baffled by the existence of magnetoelectric multiferroics since the conditions for either ferroic order appear to be mutually exclusive. Ferromagnetism occurs in transition metal compounds, in which cations have their $d$ subshells partially occupied by electrons. The ligands are positioned symmetrically around the metal ion. On the other hand, ferroelectricity favours insulators-systems with empty $d$ subshells and a non-centrosymmetric ligand field surrounding the cation [9, $14,25]$. While the cause of (ferro)magnetism is straightforward and involves exchange interactions between spins and ordering of magnetic moments, the mechanisms of ferroelectricity are more diverse and complicated. These include: ferroelectricity due to lone electron pairs, charge ordering, geometric ferroelectricity and ferroelectricity due to spin-driven mechanisms (e.g., inverse Dzyaloshinskii-Moriya interaction) $[4,9,14]$.

Multiferroics can exist as either single-phase compounds or composites and can be classified into two basic groups. In type-I multiferroics, magnetic and ferroelectric orders occur at different temperatures (possibly above room temperature) and their mechanisms are independent of one another. Such materials feature a relatively weak ME coupling. In type-II multiferroics, ferroelectric response is triggered by magnetic phenomena in the material. Although ME coupling tends to be stronger than 
in the former case, it is usually achieved at cryogenic temperatures at which non-zero polarization occurs [14]. Despite this drawback, a few novel type II materials have been discovered (e.g., hexaferrites) that yield responses of the applicable order at room temperature $[15,16]$.

Magnetoelectric multiferroics promise a wide range of potential applications, predominantly in disciplines like physics, materials science and engineering. The materials can be utilized as transducers and magnetic field sensors in metrology, more efficient non-volatile memory (use of electric fields instead of magnetic ones), logic elements, frequency-sensitive capacitors in electronics and spintronics or diodes in photovoltaics. Last but not least, multiferroics can increase the chances of combating cancer via new diagnostics and drug delivery methods in medicine $[9,17,25,29]$.

\section{Magnetoelectric coupling coefficient}

The ME coupling coefficient can be obtained by examining the free energy $F$ function of a crystal according to the Landau theory of phase transition $[1,8,10,22,24]$ :

$$
\begin{aligned}
& F(E, H)=F_{0}-P_{i}^{S} E_{i}-M_{i}^{S} H_{i}-\frac{1}{2} \varepsilon_{0} \varepsilon_{i j} E_{i} E_{j}-\frac{1}{2} \mu_{0} \mu_{i j} H_{i} H_{j} \\
& -\alpha_{i j} E_{i} H_{j}-\frac{\beta_{i j k}}{2} E_{i} H_{j} H_{k}-\frac{\gamma_{i j k}}{2} H_{i} E_{j} E_{k}-\ldots
\end{aligned}
$$

where: $F_{0}-$ free energy of a disordered system; $P_{i}^{S}, M_{i}^{S}-$ spontaneous polarization and magnetization; $\varepsilon_{0}-$ vacuum permittivity; $\varepsilon_{i j}$ - relative permittivity; $\mu_{0}$ - vacuum permeability; $\mu_{i j}$ - relative permeability; $\alpha_{i j}, \beta_{i j k}, \gamma_{i j k}$ - magnetoelectric coupling coefficients of successive orders of magnitude [8, 10, 24].

The function $F$ is represented as Maclaurin power series in terms of an external electric field $E$ and magnetic field $H$. The indices $i, j$ and $k$ correspond to $x, y$ and $z$ axes. Einstein summation convention regarding the same two subscripts in each term is implied [8, 22]. The first term represents free energy of a disordered (high-temperature) phase. The second and third terms quantify energy contributions caused by spontaneous polarization and magnetization, respectively. The fourth and fifth terms account for material response to an electric or magnetic field. The sixth term corresponds to the linear ME coupling. The secondrank tensor $\alpha_{i j}$ stands for the linear ME coupling coefficient, whereas higher-order (quadratic) ME effects are denoted by thirdrank tensors $\beta_{i j k}$ and $\gamma_{i j k}$. These tensor coefficients are measured in $\left[\mathrm{sm}^{-1}\right]$ in SI units $[8,10,22]$. Unless it is specified, the ME coupling under investigation should be understood as a linear effect.

By differentiating equation (1) with respect to $E_{i}$ or $H_{i}$ and then setting $E_{j}$ and $H_{j}$ respectively as 0 , the following $\mathrm{ME}$ responses are obtained $[8,10,22]$ :

$$
\begin{gathered}
P_{i}(H)=P_{i}^{S}+\alpha_{i j} H_{j}+\frac{\beta_{i j k}}{2} H_{j} H_{k}+\ldots \\
M_{i}(E)=M_{i}^{S}+\alpha_{j i} E_{j}+\frac{\gamma_{i j k}}{2} E_{j} E_{k}+\ldots
\end{gathered}
$$

An important difference should be noted between these equations, namely the change $\alpha_{i j} \rightarrow \alpha_{j i}$. The latter coefficient quantifies the (linear) inverse ME coupling.

Finally, a clear representation of the ME coupling coefficient is obtained with further differentiation:

$$
\begin{gathered}
\alpha_{i j}^{H}=\frac{\partial P_{i}}{\partial H_{j}} \\
\alpha_{j i}^{E}=\frac{\partial M_{i}}{\partial E_{j}}
\end{gathered}
$$

The superscripts inform as to the source of the ME coupling. The second rank tensor $\alpha_{i j}$ takes the form of a $3 \times 3$ matrix:

$$
\alpha_{i j}^{H}=\left[\begin{array}{lll}
\alpha_{x x} & \alpha_{x y} & \alpha_{x z} \\
\alpha_{y x} & \alpha_{y y} & \alpha_{y z} \\
\alpha_{z x} & \alpha_{z y} & \alpha_{z z}
\end{array}\right] \equiv \alpha
$$

In most cases, only one out of nine components is non-zero due to crystal symmetry of the sample and external fields geometry considerations [28]. In polycrystalline multiferroics, the ME coupling coefficient is a scalar quantity [28]. The extent of the $\mathrm{ME}$ response is then limited by the condition:

$$
\alpha^{2} \leq \varepsilon_{0} \mu_{0} \varepsilon_{r} \mu_{r}
$$

where: $\varepsilon_{r}$-relative permittivity, $\mu_{r}$ - relative permeability $[8,28]$.

An alternative, thermodynamic approach to multiferroic single-phase and composite systems can be found in [29]

\section{Measurement techniques}

There are two challenges that dominate the multiferroic research. Firstly, a material with sufficiently strong, roomtemperature ME coupling for large-scale commercial use has not been identified yet. Secondly, the measurement techniques used in multiferroic research are often problematic to implement in a laboratory setting and, despite being thoroughly studied, fail to yield reproducible results. The known experimental methods are classified as direct or indirect. Direct methods assign a numerical value to the ME coupling coefficient, whereas indirect methods just inform about the presence of the phenomenon in the measured sample. Furthermore, indirect methods are usually insufficient to determine multiferroicity on their own and require additional studies [3, 28]. The following subsections describe three most commonly used methods in multiferroic studies; the lock-in technique, the Sawyer-Tower (S-T) circuit and dielectric constant measurements.

\subsection{Lock-in technique}

The lock-in technique, also known as the dynamic method, takes its name from the key component of the experimental set-up - a lock-in amplifier. In this method, a multiferroic sample (monoor polycrystalline) is exposed to a sinusoidal, alternating current (AC) magnetic field with an additional direct current (DC) bias. The superimposed fields lead to electric polarization of the material via the magnetoelectric effect. The resultant voltage $V$ across the sample is measured by the frequency-attuned lock-in amplifier. The ME coupling coefficient is then calculated based on the gathered data $[19,21,22,28]$.

The experimental set-up consists of the following components:

- a pair of Helmholtz coils,

- electromagnet with a power source,

- Hall probe,

- function generator,

- lock-in amplifier,

- PC with LabView software,

- multimeter,

- sample $[7,11]$.

The way the different components are connected is presented in Fig. 2.

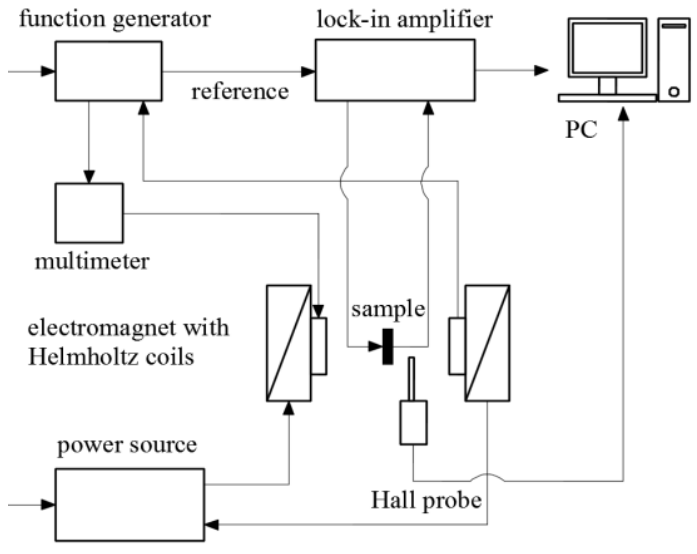

Fig. 2. The lock-in technique experimental set-up 
A pellet-shaped sample is placed inside a pair of Helmholtz coils, between the poles of a DC electromagnet. The sample is oriented perpendicular to the magnetic field lines and its position ensures excitation filed uniformity. A Hall probe placed next to the sample measures the intensity of the DC bias field. The field typically takes values from a range of $\pm 15 \mathrm{kOe}$ (1 Oe $=79.577 \mathrm{Am}^{-1}$ in SI units) [7, 11, 18, 28]. The Helmholtz coils connected to a function generator generate an AC field at frequency $f$ (usually up to $10 \mathrm{kHz}$ ) and intensity of about $20 \mathrm{Oe}$. The exact field intensity can be calculated with an appropriate formula by measuring the driving current in the circuit. The sample is connected via electrodes to the lock-in amplifier operating in the voltage differential mode.

The lock-in amplifier is an instrument used for tracking and amplification of weak signals in the presence of background noise. Its working principle is simple. The device utilizes a phasesensitive detection technique to pick out and follow signals with a given frequency and phase shift. This is achieved by comparing a noisy input signal with a reference signal (e.g., from a function generator) continuously in real-time. The noisy voltage signal is first amplified and passed through a bandpass filter. The lock-in amplifier tracks the signal parameters and makes adjustments to the reference signal accordingly. Both signals are multiplied by a special rectifier- the phase-sensitive detector. If the frequencies and phases match, a DC signal proportional to the original is obtained. The signal is then passed through a low pass filter and amplified. The values can be read directly from the device or processed with a computer interfaced with the amplifier (data acquisition card required) [30].

Finally, the voltage ME coupling coefficient is calculated from the collected data:

$$
\alpha_{V}^{H}=\frac{1}{t}\left(\frac{\partial V}{\partial H}\right)=\frac{V_{\omega}}{t h_{0}}=\frac{\alpha+2 \beta H+3 \gamma H^{2}+\ldots}{t}
$$

where: $t$ - sample thickness, $V_{\omega}-$ first harmonic of the magnetically induced voltage, $h_{0}-\mathrm{AC}$ magnetic field amplitude, $H$ - DC magnetic field amplitude.

The unit of the voltage coefficient is $\mathrm{Vcm}^{-1} \mathrm{Oe}^{-1}$ [28]. Equation (6) leads to an important observation. If a DC bias is used in the experiment, the calculated coefficient is not truly linear. In fact, it is called a pseudo-linear coefficient which value depends on the contribution from higher-order ME coefficients [22]. In reality, an AC excitation field alone is usually not enough to conduct the measurements [28].

Despite the amplifier ability to deal with noisy signals, noise can have a meaningful impact on the outcome of the experiment. It is always important to identify the sources of noise and eliminate or reduce their influence. Noise can be intrinsic (inherent to all physical processes) or external (due to environmental factors) [30]

Types of noise:

1) Intrinsic noise sources:

- Johnson noise - an electronic noise due to thermal agitation of charge carries in a conducting material [30],

- shot noise (granular noise) - an electronic noise caused by the discrete nature and statistical independence of individual charge carriers [30, 31],

- $\quad 1 / \mathrm{f}$ (flicker noise) - an electronic noise which is presumably linked to fluctuating domains and defects in a material structure [30, 32],

2) Extrinsic noise sources:

- capacitive coupling - parasitic capacitance between electrical conductors. Two parallel conductors at different potentials and in close proximity act as capacitors plates [30, 33],

- inductive coupling - a noise voltage generated by an AC in one conductor which induces an EMF (electromotive force) in a nearby second conductor via Faraday's law of induction $[30,33]$,

- ground loops - multiple ground points in an electrical circuit can create a current loop that picks up noise [30],

- microphonics - mechanical vibrations cause a noise current in an electrical circuit [30],
- thermocouple effects - a junction of two dissimilar metals generates a thermoelectric EMF if the metals are at different temperatures [30].

\subsection{Sawyer-Tower circuit}

The Sawyer-Tower (S-T) circuit is an indirect method of multiferroic investigation. Originally, the circuit is a simple way to characterize dielectric materials - observe and measure their electrical hysteresis under variable electric field intensity $[5,6]$. The electric polarization in multiferroics is non-linear, therefore the confirmation of the ME effect can be readily made with minor modifications to the original circuit [28]. The method should be treated as a tool for preliminary ferroelectric and multiferroic studies.

The basic Sawyer-Tower circuit consists of the following components:

- function generator,

- high-voltage (HV) amplifier,

- resistive voltage divider,

- capacitive voltage divider,

- compensation circuit,

- oscilloscope,

- data acquisition (DAQ) card,

- PC,

- sample [5, 26].

The following schematic (Fig. 3) shows the basic S-T circuit experimental set-up.

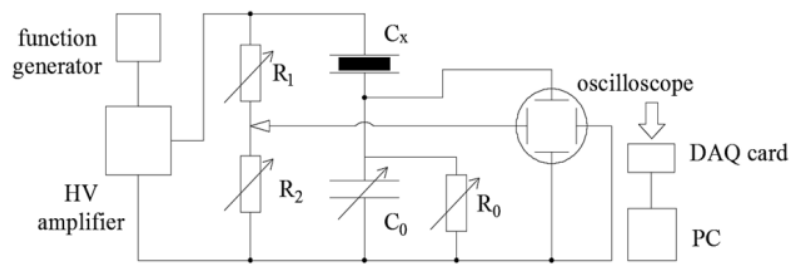

Fig. 3. The Sawyer-Tower circuit experimental set-up

In the basic design, a signal generator with a high-voltage amplifier supplies the S-T circuit with a sinusoidal signal. The circuit consists of two voltage dividers; resistive $\left(R_{1}\right.$ and $\left.R_{2}\right)$ and capacitive (a measured sample $C_{x}$ and a decade capacitor $C_{0}$ ). The output voltage of the first divider registered by the horizontal plates of the oscilloscope. The voltage across the capacitor $C_{0}$ is measured by the vertical plates. The oscilloscope works in XY mode and the perpendicular signals result in a two-dimensional, real-time function $P(E)$ being displayed on the oscilloscope screen. The circuit might be additionally equipped with a compensation to counter the effects of dielectric losses (frequency- and capacitance-dependent dissipation of energy of a material [5]. The compensation follows the formula:

$$
R_{\mathrm{o}} C_{\mathrm{o}}=R_{x} C_{x}
$$

where $R_{x}-$ resistance of the sample.

The data can be processed further by means of suitable software. A connection between the experimental set-up and a computer can be established with a DAQ card $[5,26]$.

Each dielectric material has a parameter known as dielectric strength. It is a field intensity limit, exceeding which leads to dielectric breakdown and damage to the sample. In multiferroic research, field intensity up to $10 \mathrm{kVcm}^{-1}$ is usually required [1]. The field can be calculated by dividing the voltage across the sample by its thickness. The voltage $U$ across the HV amplifier terminals is measured with a voltmeter and is equal to:

$$
U=U_{x}+U_{0}=U_{x}+\frac{C_{x}}{C_{0}} U_{x}=U_{x}\left(1+\frac{C_{x}}{C_{0}}\right)
$$

where $U_{x}$ - voltage across the sample, $U_{0}$ - voltage across the capacitor $\mathrm{C}_{0}$.

Since $C_{x} \ll C_{0}$, it follows that $U \approx U_{x}$. 
As far as multiferroic studies with the S-T circuit are concerned, the experimental process relies on the monoor polycrystalline sample being additionally placed between the poles of an electromagnet. Polarization information regarding the ME effect is acquired by changing the intensity of a magnetic field. Since the method is based on visual observation rather than obtaining numerical values, it is important to distinguish between valid results and artifacts. In some cases, a hysteresis might appear to be deformed or be in fact a Lissajous figure (the sample is not multiferroic). One such negative contribution to the experiment is the aforementioned dielectric loss [6].

\subsection{Dielectric constant measurements}

Dielectric constant (relative permittivity) measurements constitute an alternative method of detecting the magnetoelectric (ME) effect. This indirect method is based on the magnetodielectric effect (MDE) which describes a relationship between magnetic induction $B$ and relative permittivity $\varepsilon$ of a material [2, 3, 20, 27]. Since a multiferroic compound relies on a magnetic field to influence its electric polarization, observable changes to its dielectric constant are to be expected.

Relative permittivity is defined as a complex number containing a real and an imaginary part:

$$
\varepsilon(\omega)=\varepsilon^{\prime}(\omega)-i \varepsilon^{\prime \prime}(\omega)
$$

where: $\varepsilon, \varepsilon "$ - real and imaginary part of relative permittivity, $\omega$ - electric field frequency [2, 27].

The Argand diagram showing components of relative permittivity on a complex plane is presented in Fig. 4.

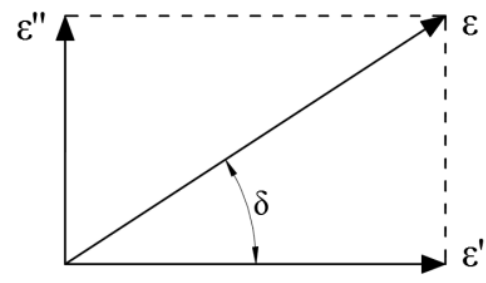

Fig. 4. Complex relative permittivity - the Argand diagram

The real component of complex relative permittivity is in phase with the excitation signal and corresponds to the energy storage capability of the material, whereas the imaginary component is out of phase and is proportional to the loss tangent $\tan \delta$ (dielectric losses) [1].

Complex relative permittivity is measured with an LCR meter or impedance analyser. The experimental set-up consists of the following components:

- LCR meter,

- sample holder (cell),

- sample $[2,12]$.

Once the sample in the form of a thin plate is connected to the LCR meter via electrodes, the basic dielectric measurements can commence. A dedicated sample holder with shielding may or may not be used to cut off external noise sources from the experiment.

A modern meter works on a principle of radio frequency current-voltage (RF I-V) measurements [34]. This allows for greater precision over a wider frequency spectrum. The meter generates a sinusoidal voltage in its internal oscillator which is then applied across the sample. The potential difference between the two electrodes, the electric current passing through them and the phase difference $\delta$ between these quantitates is measured. The LCR meter derives the value of impedance from acquired data which can also be presented in terms of inductance $L$, capacitance $C$ and resistance $R$ with the use of a phase-sensitive detector $[34,35]$. For high-accuracy impedance measurements, Kelvin (4-wire) method is often utilized to eliminate errors due to wire resistance [35].
There are numerous methods of measuring relative permittivity with an LCR meter. Depending on the available equipment, effective testing standards and required precision, each solution has respective guidelines and formulas to follow. Their description is beyond the scope of this article. The contacting and non-contacting electrode (air-gap) methods are the two simplest ways of obtaining the desired quantity. In essence, they both involve two capacitance and tangent loss measurements; one with the dielectric inserted between the meter electrodes and one without the dielectric. Such a procedure mirrors the physical interpretation of relative permittivity. From a theoretical standpoint, the real part of complex relative permittivity is equal to:

$$
\varepsilon^{\prime}=\frac{C_{x}}{C_{0}}
$$

where $C_{x}-$ capacitance with an inserted dielectric, $C_{0}$ - capacitance of air or vacuum $[1,23]$.

Based on Fig. 4, the imaginary part is calculated from the following trigonometric identity:

$$
\varepsilon^{\prime \prime}=\varepsilon^{\prime} \tan \delta
$$

In order to test a multiferroic materials for the presence of the MDE effect, a sample is additionally placed between the evenlyspaced poles of an electromagnet. The measurements are carried out with the static magnetic field turned on and off. The data is required to calculate the following parameters:

- magnetocapacitance (MC):

$$
M C=\frac{\varepsilon^{\prime}(B)-\varepsilon^{\prime}(0)}{\varepsilon^{\prime}(0)}
$$

where: $\varepsilon^{\prime}(B), \varepsilon^{\prime}(0)$ - relative permittivity measured under an AC electric field with a magnetic field turned on and off [3, 27].

- magnetolosses (ML):

$$
M L=\frac{\tan \delta(B)-\tan \delta(0)}{\tan \delta(0)}
$$

where: $\tan \delta(\mathrm{B}), \tan \delta(0)$ - loss tangent measured under an $\mathrm{AC}$ electric field with a magnetic field turned on and off [3, 27].

- magnetoresistance (MR):

$$
M R=\frac{\Delta \rho}{\rho}=\frac{\rho(B)-\rho(0)}{\rho(0)}=\frac{R(B)-R(0)}{R(0)}
$$

where: $\rho$ - resistivity, $R$ - electrical resistance $[2,3,13]$.

Average experimental conditions are as follows: sample thickness: $1 \mathrm{~mm}$; frequency range: $10^{2} \div 10^{6} \mathrm{~Hz}$; magnetic field strength: $\pm 10 \mathrm{kOe}$ and electric field strength: $1 \mathrm{Vmm}^{-1}[2,12,27]$.

The largest single drawback of relative permittivity measurements is that they are not completely reliable when it comes to confirming the occurrence of the ME effect. The MDE effect can take place in materials which are not multiferroic in nature. Magnetocapacitance may have a non-zero value due to a number of intrinsic and extrinsic contributions, such as: sample inhomogeneity, change of polarization of oxygen octahedra owing to interaction between a magnetic field and $\mathrm{Fe}$ ions, antiferromagnetic spin fluctuations, etc. [2, 3, 27]. The most common factors causing ME-unrelated magnetocapacitance are magnetoresistance and the creation of interfaces (e.g., grain boundaries) in singe crystals, polycrystalline and composite samples. The latter phenomenon is described and modelled by the Maxwell-Wagner effect [2, 3].

\section{Conclusion}

Multiferroics are a group of electrical insulators which feature interesting magnetic and electrical properties. The magnetoelectric effect can be used in a variety of disciplines ranging from energy harvesting to medical applications. The perspectives on the future of multiferroic research appear to be brighter than ever. There is a great deal of pressure to discover and commercialize new materials. One can easily observe global trends regarding clean energy, advancements in technologies like quantum computing 
or rising rates of cancer or other debilitating conditions that demand new diagnostics and treatment methods.

The lock-in technique, Sawyer-Tower circuit and dielectric measurements are the simplest and most affordable measurement techniques in multiferroic research. Problems with accuracy and result reproducibility show that more emphasis should be put on novel experimental techniques by the scientific community. New multiferroics exhibiting previously unknown phenomena encourage constant adaptation of the existing methods and innovation.

\section{References}

[1] Bain A. K., Chand P.: Ferroelectrics: Principles and Applications. Wiley, 2017

[2] Bonaedy T, Koo Y. S., Sung K. D., Jung J. H.: Resistive magnetodielectric property of polycrystalline $\gamma-\mathrm{Fe}_{2} \mathrm{O}_{3}$. Applied Physics Letters 91(13)/2007, 132901 [http://doi.org/10.1063/1.2790474].

[3] Catalan G.: Magnetocapacitance without magnetoelectric coupling. Applied Physics Letters 88(10)/2006, 102902 [http://doi.org/10.1063/1.2177543].

[4] Cheong S.-W., Mostovoy M.: Multiferroics: a magnetic twist for ferroelectricity. Nature Materials 6(1)/2007, 13-20 [http://doi.org/10.1038/nmat1804].

[5] Das C., Shahee A., Lalla N., Shripathi T.: A simple and low cost Sawyer-Tower ferro-electric loop tracer with variable frequency and compensation circuit. Proceedings of the 54th DAE Solid State Physics Symposium, 2009, 439.

[6] Dawber M., Rabe K. M, Scott J. F.: Physics of thin-film ferroelectric oxides. Reviews of Modern Physics 77(4)/2005, 1083 [http://doi.org/10.1103/RevModPhys.77.1083].

[7] Duong G. V., Groessinger R., Schoenhart M., Bueno-Basques D.: The lock-in technique for studying magnetoelectric effect. Journal of Magnetism and Magnetic Materials 316(2)/2007, 390-393 [http://doi.org/10.1016/j.jmmm.2007.03.185].

[8] Eerenstein W., Mathur N. D., Scott J. F. Multiferroic and magnetoelectric materials. Nature (7104)/2006, 759-765 [http://doi.org/10.1038/nature05023].

[9] Fiebig M., Lottermoser T., Meier D., Trassin M.: The evolution of multiferroics. Nature Reviews Materials 1/2016, 16046 [http://doi.org/10.1038/natrevmats.2016.46].

[10] Fiebig M.: Revival of the magnetoelectric effect. Journal of Physics D: Applied Physics 38(8)/2005, R123 [http://doi.org/10.1088/0022-3727/38/8/R01].

[11] Fuentes-Cobas L. E., Matutes-Aquino J. A., Fuentes-Montero M. E.: Handbook of Magnetic Materials, Chapter 3- Magnetoelectricity. Elsevier, 2011

[12] Guobin C., Hui Y., Xiaoming Z., Jun L., Jun T.: Clarification of the Magnetocapacitance Mechanism for $\mathrm{Fe}_{3} \mathrm{O}_{4}$-PDMS Nanocomposites. Journal of Nanomaterials 2015/2015, 982174 [http://doi.org/10.1155/2015/982174].

[13] Hishiyama Y., Kaburagi Y., Inagaki M.: Materials Science and Engineering of Carbon: Characterization. Elsevier, 2016

[14] Khomskii D.: Classifying Multiferroics: Mechanisms and Effects. Physics 2/2009 [http://doi.org/10.1103/Physics.2.20].

[15] Kimura T.: Magnetoelectric Hexaferrites. Annual Review of Condensed Matter Physics 3(1)/2012, 93-110 [http///doi.org/10.1146/annurev-conmatphys020911-125101].

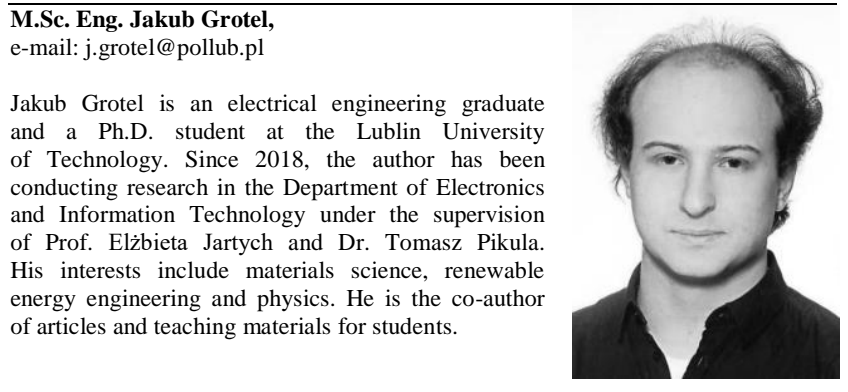

http://orcid.org/0000-0001-8428-2292

otrzymano/received: 01.03.2021 przyjęto do druku/accepted: 15.03 .2021
[16] Kitagawa Y., Hiraoka Y., Honda T., Ishikura T., Nakamura H., Kimura T.: Low-field magnetoelectric effect at room temperature. Nature Materials 9(10)/2010, 797-802 [http://doi.org/10.1038/nmat2826].

[17] Kreisel J., Kenzelmann M.: Multiferroics - the challenge of coupling magnetism and ferroelectricity. Europhysics News 40(5)/2009, 17-20 [http://doi.org/10.1051/epn/2009702].

[18] Kuila S., Tiwary S., Sahoo M. R., Barik A., Vishwakarma P. N.: Measurement of temperature dependent magnetoelectricity in $\mathrm{BiFe}_{(1-\mathrm{x})} \mathrm{Co}_{\mathrm{x}} \mathrm{O}_{3} ; \mathrm{x}=0,0.01$, 0.02. Journal of Alloys and Compounds 709/2017, 158-164 [http://doi.org/10.1016/j.jallcom.2017.03.118].

[19] Mahesh Kumar M., Srinivas A., Suryanarayana S. V., Kumar G. S., Bhimasankaram T.: An experimental setup for dynamic measurement of magnetoelectric effect. Bulletin of Materials Science 21(3)/1998, 251-255 [http://doi.org/10.1007/BF02744978].

[20] Parish M. M.: Magnetocapacitance without magnetism. Philosophical Transactions of the Royal Society A: Mathematical, Physical and Engineering Sciences 372(2009)/2014 [http://doi.org/10.1098/rsta.2012.0452].

[21] Rivera J. P.: A short review of the magnetoelectric effect and related experimental techniques on single phase (multi-) ferroics. The European Physical Journal B 71/2009, 299 [http://doi.org/10.1140/epjb/e2009-00336-7].

[22] Rivera J. P.: On definitions, units, measurements, tensor forms of the linear magnetoelectric effect and on a new dynamic method applied to $\mathrm{Cr}-\mathrm{Cl}$ boracite. Ferroelectrics 161(1)/1994, 165-180 [http://doi.org/10.1080/00150199408213365]

[23] Serway R., Jewett Jr. J. W.: Physics for Scientists and Engineers. Cengage Learning, 2014

[24] Siratori K., Kohn K., Kita E.: Magnetoelectric Effect in Magnetic Materials. Acta Physica Polonica A 81/1992, 431-466 [http://doi.org/10.12693/APhysPolA.81.431].

[25] Spaldin N. A., Cheong S.-W., Ramesh R.: Multiferroics: Past, present, and future. Physics Today 63(10)/2010, 38-43 [http://doi.org/10.1063/1.3502547].

[26] Stewart M., Cain M., Hall D.: Ferroelectric Hysteresis Measurement and Analysis. NPL Report 152, 1999.

[27] Turik A. V., Pavlenko A. V.: Magnetodielectric Effect and Magnetoelectricity in Multiferroics and Heterogeneous Systems: Modeling and Experiment. Ferroelectrics 444(1)/2013, 53-59 [http://doi.org/10.1080/00150193.2013.786308].

[28] Vopson M. M., Fetisov Y. K., Caruntu G., Srinivasan G.: Measurement Techniques of the Magneto-Electric Coupling in Multiferroics. Materials 10(8)/2017 [http://doi.org/10.3390/ma10080963]

[29] Vopson M. M.: Fundamentals of Multiferroic Materials and Their Possible Applications. Critical Reviews in Solid State and Materials Sciences 40(4)/2015, 223-250 [http://doi.org/10.1080/10408436.2014.992584].

[30] Stanford Research Systems, Inc., Model SR830 DSP Lock-In Amplifier. User Manual, 2011.

[31] http://physicsopenlab.org/2016/10/10/shot-noise-and-electron-charge/ (available: 02.2021)

[32] http://www.scholarpedia.org/article/1/f_noise (available: 02.2021).

[33] https://techweb.rohm.com/knowledge/emc/s-emc/01-s-emc/6943 (available: 02.2021).

[34] https://www.electronics-notes.com/articles/test-methods/lcr-meterbridge/primer-basics.php (available: 02.2021)

[35] https://www.voltech.com/Products/DC1000A/Howitworks.aspx (available: 02.2021) 